\title{
Pregnant at Time of Vaccination
}

National Cancer Institute

\section{Source}

National Cancer Institute. Pregnant at Time of Vaccination. NCI Thesaurus. Code C162844.

An individual was pregnant at the time a vaccination was administered. 